\title{
Modelling of global solar irradiance on sloped surfaces in climatic conditions of Kraków
}

\author{
Piotr Michalak \\ AGH University of Science and Technology, Poland
}

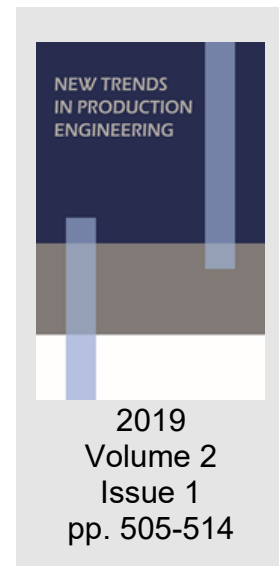

Date of submission to the Editor: 05/2019

Date of acceptance by the Editor: 08/2019

\section{INTRODUCTION \\ Background}

External climatic conditions have strong impact on the energy use for space heating and cooling of buildings (Wojdyga, 2008). One of them is solar radiation incident on external surfaces and transmitted through windows into an internal space of a building. Thus solar heat gain is a significant element of thermal balance of each building.

In Poland, in 2008, files containing typical meteorological years (TMYs) in the hourly data format and based on them monthly statistical data were developed and have been made publicly available at no charge (MliR, 2019). In addition to the basic climate parameters (air temperature, barometric pressure, relative humidity, wind speed and direction), they also include hourly global solar irradiance on a horizontal surface and inclined surfaces $\left(30^{\circ}, 45^{\circ}, 60^{\circ}\right.$ and $\left.90^{\circ}\right)$ oriented in eight basic directions (N, NE, E, SE, S, SW, W and NW). They were prepared for the buildings' energy calculations using methods from EN ISO 13790 (The Polish Committee for Standardization, 2009).

In 2017 a new PN-EN ISO 52010-1 standard (The Polish Committee for Standardization, 2017) was published. The introduction of the new standard means that impact of modelling methods to obtain global solar irradiance incident on a building's envelope on its calculated annual energy demand for space heating and cooling should be estimated.

\section{LITERATURE REVIEW}

In meteorological stations global horizontal and additionally direct (beam) and diffuse horizontal irradiances are measured (Mazurek, 2014). But in technical applications inclined and vertical surfaces are usually found (solar collectors, PV panels or external walls of buildings). Because of that a number of mathematical models for the calculation of solar irradiance incident on sloped surfaces, using the solar irradiance data from meteorological measurements, over the last few decades have been developed. These models, as well as TMYs, were used also 
in Polish conditions. Cyrankowski et. al. (Cyrankowski et al., 2014) showed calculations of the heating and cooling energy demand of a single family house using the simple hourly method of PN-EN ISO 13790. The TMY for the Warszawa-Okęcie weather station was used. In another paper (Basińska et al., 2018) a theoretical energy demand of two apartments in a residential building was compared with measurements in the period 2010-2017. Climatic data were taken from the meteorological station Poznań-Ławica and from the TMY for Poznań. Authors stated that the energy assessment of a building depends on input weather data and calculation assumptions.

In (Grudzińska and Jakusik, 2015) and (Grudzińska and Jakusik, 2015) the energy demand for heating and cooling of a single flat in a multifamily residential building located in Warsaw (central Poland), Wieluń (central-south Poland), Włodawa (central-east Poland) and Łeba (Baltic Coast) was calculated using two weather datasets and the BSim tool. In each location the TMY and climatic data from measurements during the 2001-2012 period were used. The heating demand calculated using the second dataset was lower by up to $11 \%$ than in the case of the TMY. The cooling demand was greater by more than $20 \%$. A similar analysis for other five locations (Koszalin, Poznań, Lublin, Białystok and Zakopane) was presented in (Grudzińska, 2016). Comparing to the TMY the heating demand was lower in a range from $2 \%$ (warmer climatic zones) to $28 \%$ (coldest zone).

Analogous considerations, but concerning photovoltaics, were shown in (Nelken and Zmudzka, 2016). The TMY's and data from measurements during the period 1971-2000 for 16 weather stations were used. Differences between these two input datasets exceeded $9 \%$.

This overview shows an impact of solar irradiance on the theoretical and real energy performance of buildings. Thus an assessment how the calculation method to obtain global solar irradiance on external surfaces influences calculated solar gains and heating demand of residential buildings is the main topic of this paper. The next section presents briefly Polish typical meteorological year. Next five transposition models to calculate global solar irradiance on sloped surfaces (Hay, Muneer, Reindl, Perez and Perez according to the PN-EN ISO 52010-1 standard) are described. Then an annual energy demand for space heating of an exemplary residential building was calculated using the monthly method from PN-EN ISO 13790. Finally the results and conclusions are presented.

\section{GLOBAL IRRADIANCE ON A SLOPED SURFACE \\ Direct and diffuse irradiance on a horizontal surface}

Files with TMYs have been prepared for 61 Polish weather stations. In each file there are given hourly values of the dry bulb temperature, relative humidity, wind speed and direction and global solar irradiance on a horizontal plane from measurements for the whole year. Using the method given in PN-EN ISO 520101 (The Polish Committee for Standardization, 2017) global horizontal irradiance can be used to obtain diffuse and direct horizontal irradiances. 


\section{Diffuse irradiance incident on a sloped surface}

To calculate global solar irradiance on a sloped surface in a given location (latitude and altitude) and known orientation (azimuth and slope angle), some additional variables should be computed at first. These are solar declination, solar time, equation of time, solar hour angle, solar altitude angle and zenith angle. They can be obtained using the method given in PN-EN ISO 52010-1 (The Polish Committee for Standardization, 2017, Michalak, 2018).

Global irradiance on a sloped surface is the sum of beam (direct), diffuse and reflected components. It can be calculated from input (measured and/or modelled) beam and diffuse horizontal irradiances using a transposition model of the form:

$$
I_{g, s}=I_{b, h} \cdot R_{b}+I_{d, h} \cdot R_{d}+\left(I_{b, h}+I_{d, h}\right) \cdot \rho \cdot R_{r}
$$

where:

$$
\mathrm{R}_{\mathrm{b}}=\cos \theta / \cos \theta_{\mathrm{z}}
$$

The ground reflected component is assumed to be isotropic (Grudzińska, 2018):

$$
\mathrm{R}_{\mathrm{r}}=(1-\cos \beta) / 2
$$

The diffuse component is given by:

$$
I_{d, s}=I_{d, h} \cdot R_{d}
$$

To calculate diffuse irradiance on a tilted surface five anisotropic transposition models were used, as follows: Hay, Muneer, Reindl, Perez and Perez according to PN-EN ISO 52010-1. They were recommended by other researchers for Polish conditions (Włodarczyk and Nowak, 2009, Frydrychowicz-Jastrzębska and Bugała, 2015). Short descriptions of all models are presented in the following sections.

\section{Transposition models}

Hay model

In this model (Hay, 1979) the Rd factor is given by:

$$
\mathrm{R}_{\mathrm{d}}=\mathrm{k}_{\mathrm{H}} \cdot \mathrm{R}_{\mathrm{b}}+0.5(1+\cos \beta) \cdot\left(1-\mathrm{k}_{\mathrm{H}}\right)
$$

where:

$$
\mathrm{k}_{\mathrm{H}}=\mathrm{I}_{\mathrm{b}, \mathrm{n}} / \mathrm{I}_{\mathrm{s}, \mathrm{c}}
$$

\section{Muneer model}

This model (Muneer and Satuja, 1989) uses a modified anisotropy index of Hay:

$$
\mathrm{k}_{\mathrm{D}}=\mathrm{I}_{\mathrm{b}, \mathrm{h}} / \mathrm{I}_{\mathrm{ext}, \mathrm{h}}
$$

with:

$$
\mathrm{I}_{\mathrm{ext}, \mathrm{h}}=\mathrm{I}_{\mathrm{ext}} \cdot \sin \alpha_{\mathrm{sol}}
$$

lext is calculated in accordance with PN-EN ISO 52010-1 (The Polish Committee for Standardization, 2017). For the slope angle $(\beta)$ in radians:

$$
\mathrm{R}_{\mathrm{d}}=\mathrm{k}_{\mathrm{D}} \cdot \mathrm{R}_{\mathrm{b}}+\left(1-\mathrm{k}_{\mathrm{D}}\right)\left[\cos ^{2}\left(\frac{\beta}{2}\right)+\mathrm{M}\left(\sin \beta-\beta \cos \beta-\pi \sin ^{2}\left(\frac{\beta}{2}\right)\right)\right]
$$


The value of the $\mathrm{M}$ variable can be modified for different locations. For Northern Europe it is recommended (Muneer and Satuja, 1989):

$$
\mathrm{M}=0.00333-0.415 \mathrm{k}_{\mathrm{D}}-0.6987 \mathrm{k}_{\mathrm{D}}^{2}
$$

\section{Reindl model}

In this model (Reindl et al., 1990) the same anisotropy index is used as previously. Then:

$$
\mathrm{R}_{\mathrm{d}}=\mathrm{k}_{\mathrm{D}} \cdot \mathrm{R}_{\mathrm{b}}+0.5(1+\cos \beta)\left(1-\mathrm{k}_{\mathrm{D}}\right)\left(1+\mathrm{k}_{\mathrm{R}} \sin ^{3}\left(\frac{\beta}{2}\right)\right)
$$

A modulating factor is given by:

$$
\mathrm{k}_{\mathrm{R}}=\sqrt{\mathrm{I}_{\mathrm{b}, \mathrm{h}} / \mathrm{I}_{\mathrm{g}, \mathrm{h}}}
$$

\section{Perez model}

This model has been developed and then validated by its authors intensively. Here its latest version (Perez et al., 1990) is used. In this model:

$$
\mathrm{R}_{\mathrm{d}}=0.5(1+\cos \beta)\left(1-\mathrm{F}_{1}\right)+\mathrm{F}_{1} \cdot \frac{\mathrm{a}}{\mathrm{b}}+\mathrm{F}_{2} \sin \beta
$$

The coefficients $a, b$ and $\varepsilon$ and are given by the following equations, respectively:

$$
\begin{gathered}
\mathrm{a}=\max [0 ; \cos \theta] \\
\mathrm{b}=\max \left[\cos \left(85^{\circ}\right) ; \cos \theta_{\mathrm{z}}\right] \\
\varepsilon=\left(\frac{I_{d, h}+I_{b, n}}{I_{d, h}}+1.041\left(\frac{\pi}{180} \theta_{z}\right)^{3}\right) /\left(1+1.041\left(\frac{\pi}{180} \theta_{z}\right)^{3}\right)
\end{gathered}
$$

The optical air mass is calculated from PN-EN ISO52010-1 (The Polish Committee for Standardization, 2017). If $\alpha_{\text {sol }}<10$, then:

$$
\mathrm{m}=1 /\left(\sin \alpha_{\text {sol }}+0.15\left(\alpha_{\text {sol }}+3.885\right)^{-1.253}\right)
$$

elsewhere:

$$
\mathrm{m}=1 / \sin \alpha_{\mathrm{sol}}
$$

Sky's brightness $\Delta$ :

$$
\Delta=\mathrm{m} \cdot \mathrm{I}_{\mathrm{d}, \mathrm{h}} / \mathrm{I}_{\text {ext }}
$$

$F_{1}$ and $F_{2}$ coefficients are defined as:

$$
\begin{gathered}
\mathrm{F}_{1}=\max \left[0 ; \mathrm{f}_{11}(\varepsilon)+\mathrm{f}_{12}(\varepsilon) \cdot \Delta+\mathrm{f}_{13}(\varepsilon) \cdot\left(\pi \cdot \theta_{z} / 180\right)\right] \\
\mathrm{F}_{2}=\mathrm{f}_{21}(\varepsilon)+\mathrm{f}_{22}(\varepsilon) \cdot \Delta+\mathrm{f}_{23}(\varepsilon) \cdot\left(\pi \cdot \theta_{z} / 180\right)
\end{gathered}
$$

Coefficients $f_{11} \ldots f_{23}$ are dependent on a sky's clearness $\varepsilon$. In each time-step they can be determined from (Perez et al., 1990).

Model of PN-EN ISO 52010-1

The PN-EN ISO 52010-1 standard introduced the model of Perez (The Polish Committee for Standardization, 2017) shown in the previous section. But the equation describing sky clearness was given in the form: 


$$
\varepsilon=\left(\frac{I_{d, h}+I_{b, n}}{I_{d, h}}+1.041\left(\frac{\pi}{180} \alpha_{s o l}\right)^{3}\right) /\left(1+1.041\left(\frac{\pi}{180} \alpha_{s o l}\right)^{3}\right)
$$

Comparing equations (16) and (22) there can be noticed that the solar zenith angle was changed into the solar altitude angle. This model was also used in calculations to evaluate impact of this error on the final results.

\section{CALCULATIONS AND RESULTS}

\section{Assumptions}

To compare the mathematical models described in the section 2.3 solar gains and heating demand of a test building was calculated. This was an exemplary typical Polish multifamily building from the 80 's after thermal refurbishment. The building is located in Kraków (50 $3^{\prime} \mathrm{N}$ and 1956' $\mathrm{E}$ ). It is north-south oriented and built on a rectangular plan of $60 \times 11 \mathrm{~m}$. The total heated area and volume are $2991.5 \mathrm{~m}^{2}$ and $7478.8 \mathrm{~m}^{3}$, respectively. Constant internal heat gains density of $4.0 \mathrm{~W} / \mathrm{m}^{2}$ and ventilation airflow of $7478.8 \mathrm{~m}^{3} / \mathrm{h}$ were assumed. The thermal resistance of external walls and roof is $4.048 \mathrm{~m}^{2} \mathrm{~K} / \mathrm{W}$ and $4.885 \mathrm{~m}^{2} \mathrm{~K} / \mathrm{W}$, respectively. Its main geometric features are shown in Table 1. Area of windows includes frames.

Table 1 Geometric parameters of the test building

\begin{tabular}{|l|c|c|c|c|c|}
\hline \multicolumn{1}{|c|}{ Orientation } & N & S & E & W & Roof \\
\hline External wall area $\left[\mathrm{m}^{2}\right]$ & 149.6 & 149.6 & 816.0 & 816.0 & 660.0 \\
\hline Area of windows $\left[\mathrm{m}^{2}\right]$ & 172.8 & 127.2 & 0.0 & 0.0 & 660.0 \\
\hline Total effective collecting area $\left[\mathrm{m}^{2}\right]$ & 97.31 & 73.09 & 1.01 & 1.01 & 7.02 \\
\hline
\end{tabular}

External walls were covered with a mineral plaster with a solar absorption coefficient $\alpha_{\mathrm{op}}=0.6$. The roof was covered with an asphalt felt with $\alpha_{\mathrm{op}}=0.9$. The long wave emissivity of external surfaces $\varepsilon \mathrm{LW}=0.9$. The external radiative heat transfer coefficient $h_{r, e}=4.6 \mathrm{~W} /\left(\mathrm{m}^{2} \mathrm{~K}\right)$. There are PVC windows and glazed balcony doors with white frames. Thermal transmittance of glazing and frame is $\mathrm{U}=1.3 \mathrm{~W} / \mathrm{m}^{2} \mathrm{~K}$ and $\mathrm{U}=1.8 \mathrm{~W} / \mathrm{m}^{2} \mathrm{~K}$, respectively. The frame factor $\mathrm{F}_{\mathrm{F}}=0.3$ and solar energy transmittance is $g_{g l}=0.75$. No shading was assumed.

To calculate a heating and cooling demand of buildings in Poland the quasisteady state monthly method of PN-EN ISO 13790 is currently used (Panek and Kwiatkowski, 2007). Poland is a country with heating dominated climate (Jędrzejuk and Dybiński, 2015), (Firląg and Piasecki, 2018). To simplify presented considerations it was therefore reasonable to limit further analysis to the heating demand.

\section{Solar gains}

For clarity the presented results of solar gains not contain the extra heat flow due to thermal radiation to the sky which in PN-EN ISO 13790 was included in solar gains for convenience.

Total annual solar gains for the tested building calculated using solar irradiance data from the TMY for Kraków amounted 529 GJ and was greater than for presented five models for which it varied from 326 GJ (Hay model) to 343 GJ 
(both Perez's models). Monthly solar gains for the roof were the same for all models and varied from $0.64 \mathrm{GJ}$ in December to $4.10 \mathrm{GJ}$ in June. Figures 1-2 show monthly solar gains for vertical external walls. Numbers from 1 to five are assigned to the considered models: Hay, Muneer, Reindl, Perez and Perez from PN-EN ISO 52010-1, respectively. The ground reflected component was omitted $(\rho=0)$.
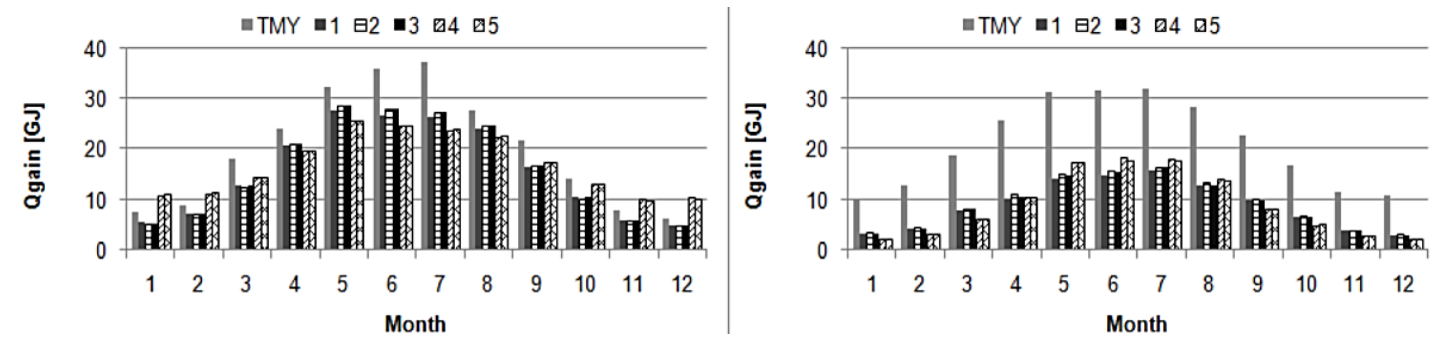

Fig. 1 Solar gains for $\mathbf{N}$ (left) and $S$ (right) walls
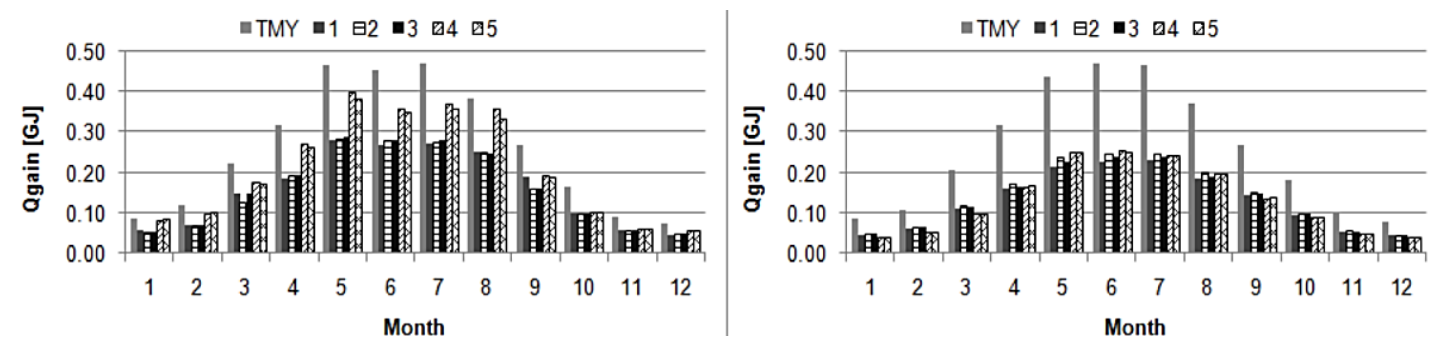

Fig. 2 Solar gains for E (left) and W (right) walls

Since input global horizontal irradiance is the same for all models, there were no differences in results for the roof. Because of their geometric and effective collecting areas, the greatest part of solar gains was received by the north and south oriented walls. Variations of annual gains calculated by five models were relatively small: from $189 \mathrm{GJ}$ (1-st model) to $204 \mathrm{GJ}$ (5), from $107 \mathrm{GJ}$ (1) to 113 GJ (2), from $1.9 \mathrm{GJ}(2)$ to $2.5 \mathrm{GJ}(4)$ and from $1.6 \mathrm{GJ}(1)$ to $1.7 \mathrm{GJ}(2)$, for the N, $\mathrm{S}, \mathrm{E}$ and $\mathrm{W}$ oriented walls, respectively. But regarding values of solar irradiance given in the TMY, resulting gains were significantly greater, and amounted (in the same order): $243 \mathrm{GJ}, 253 \mathrm{GJ}, 3.1 \mathrm{GJ}$ and $3.1 \mathrm{GJ}$ what means $23 \%, 131 \%$, $46 \%$ and $91 \%$ differences.

\section{Heating demand}

The annual energy demand for space heating $\left(\mathrm{Q}_{\mathrm{H}}\right)$ of the considered building was from 973 GJ (5) to 989 GJ (1) compared to $891 \mathrm{GJ}$ calculated using the TMY. Its monthly variation for all models is shown in Figure 3.

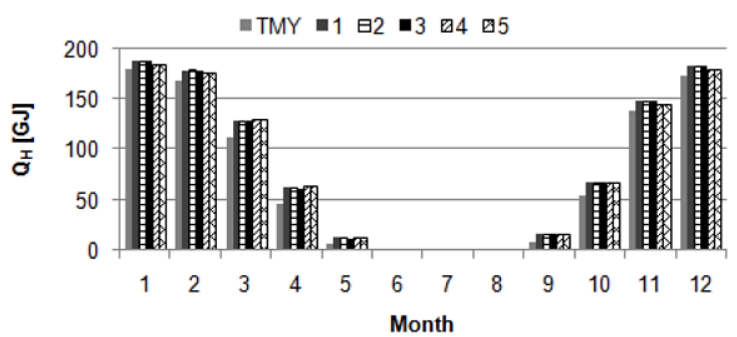

Fig. 3 Monthly heating demand of the building 
In spite of the noticeable differences in solar gains, differences in monthly heating demand were smaller. But this conclusion, without more detailed analysis, may be misleading. Dividing the value of the $Q_{H}$ by the heated area a unit heating demand $E_{A}$ in $\mathrm{kWh} / \mathrm{m}^{2}$ is obtained (Wierciński and SkotnickaSiepsiak, 2012), (Lis, 2018). For the analysed building it was from $90.4 \mathrm{~kW} / \mathrm{m}^{2}$ (4-th and 5-th model) to $91.9 \mathrm{kWh} / \mathrm{m}^{2}$ (1) with $91.2 \mathrm{kWh} / \mathrm{m}^{2}$ on average, what was $10.2 \%$ greater than the reference value of $82.8 \mathrm{kWh} / \mathrm{m}^{2}$ for the TMY. It means that the energy rating of a building changed without modernisation, resulting only from the different calculation method to obtain solar irradiance incident on a building's envelope.

\section{CONCLUSIONS}

Five transposition models to obtain global solar irradiance, incident on an arbitrarily oriented surface, were presented. All of them may use as the input data global horizontal irradiance from Polish typical meteorological years.

These models were compared in calculations of solar gains of the exemplary multifamily residential building in reference to the currently used solar irradiance data from the typical meteorological year for Kraków. The largest portion of solar gains was transferred into the building's zone through the north oriented wall and it was on average $197 \mathrm{GJ}$ (243 GJ from the TMY), comparing to $109 \mathrm{GJ}$ for the south direction (253 GJ for the TMY).

Presented models provided very similar results of monthly irradiance on vertical walls. Annual solar gains varied for the cold half year from $45.6 \mathrm{GJ}(2)$ to 70.4 GJ (5), from $22.2 \mathrm{GJ}(4)$ to $30.3 \mathrm{GJ}(2)$, from $1.4 \mathrm{GJ}(2)$ to $1.9 \mathrm{GJ}$ (4 and 5) and from 1.16 GJ (1) to 1.25 GJ (2) for the N, S, E and W oriented walls, respectively. For the warm half year (months from IV to IX) solar gains varied from $133 \mathrm{GJ}$ (4) to $147 \mathrm{GJ}(3)$, from $78 \mathrm{GJ}(1)$ to $87 \mathrm{GJ}(4)$, from $1.4 \mathrm{GJ}(2)$ to $1.9 \mathrm{GJ}(4)$ and from 1.16 GJ (1) to 1.25 GJ (2) also for the N, S, E and W oriented walls, respectively. Values from the TMY amounted 179 GJ, 172 GJ, 2.4 GJ and 2.34 GJ in the same order.

The biggest differences between the values from TMY and calculated by presented models were noticed for the south wall and, on average, amounted $67.2 \%$ and $-51.9 \%$ for the cold and warm half-year, respectively.

What is also important, the mistake in the PN-EN ISO 52010-1 standard shown in the section 2.3.5 influenced final results. Differences between values of annual irradiance from the standard and the original Perez's model were from $0.07 \%$ (west) to $2.9 \%$ (south). This statement provides very important conclusion that the calculation method to obtain global solar irradiance incident on external walls of a building has impact on its heating demand and theoretical building's energy rating.

\section{NOMENCLATURE}

$A_{\text {sol }}$ effective collecting area of an envelope element, $\mathrm{m}^{2}$

$E_{A}$ annual heating energy demand per unit floor area of a building, $\mathrm{kWh} / \mathrm{m}^{2}$ $F_{F}$ frame area fraction of the glazed element, 
$F_{1}$ circumsolar brightness coefficient,

$\mathrm{F}_{2}$ horizontal brightness coefficient,

$\mathrm{I}_{\mathrm{s}, \mathrm{c}}$ solar constant, $1370 \mathrm{~W} / \mathrm{m}^{2}$,

$\mathrm{I}_{\mathrm{b}, \mathrm{h}}$ direct (beam) solar irradiance on a horizontal surface, $\mathrm{W} / \mathrm{m}^{2}$

$\mathrm{I}_{\mathrm{b}, \mathrm{s}}$ direct (beam) solar irradiance on a sloped surface, $\mathrm{W} / \mathrm{m}^{2}$

$I_{d, h}$ diffuse solar irradiance on a horizontal surface, $\mathrm{W} / \mathrm{m}^{2}$

$I_{d, s}$ diffuse solar irradiance on a sloped surface, $\mathrm{W} / \mathrm{m}^{2}$

$l_{\text {ext }}$ extra-terrestrial irradiance, $\mathrm{W} / \mathrm{m}^{2}$

$l_{\text {ext,h }}$ extra-terrestrial irradiance on a horizontal surface, $\mathrm{W} / \mathrm{m}^{2}$

$\mathrm{I}_{\mathrm{g}, \mathrm{h}}$ global solar irradiance on a horizontal surface, $\mathrm{W} / \mathrm{m}^{2}$

$\mathrm{I}_{\mathrm{g}, \mathrm{s}}$ global solar irradiance on a sloped surface, $\mathrm{W} / \mathrm{m}^{2}$

$I_{r, s}$ solar irradiance due to ground reflection on a sloped surface, $\mathrm{W} / \mathrm{m}^{2}$

$\mathrm{R}_{\mathrm{b}}$ beam (direct) transposition factor,

$R_{d}$ diffuse transposition factor,

$\mathrm{R}_{\mathrm{r}}$ reflected transposition factor,

$\mathrm{U}$ thermal transmittance, $\mathrm{W} /\left(\mathrm{m}^{2} \cdot \mathrm{K}\right)$

$\mathrm{f}$ brightness coefficient (Perez model),

$g_{g l}$ monthly mean effective total solar energy transmittance,

$\mathrm{k}_{\mathrm{D}}$ anisotropy index (Muneer model),

$\mathrm{k}_{\mathrm{H}}$ anisotropy index (Hay model),

$\mathrm{k}_{\mathrm{R}}$ modulating factor (Reindl model),

$\mathrm{k}_{\mathrm{T}}$ clearness index of the atmosphere,

$\mathrm{m}$ air mass,

$\Delta$ sky brightness parameter,

$\alpha_{\mathrm{op}}$ absorption coefficient for solar radiation of the opaque element,

$\alpha_{\text {sol }}$ solar altitude angle, ${ }^{\circ}$

$\beta$ slope angle of inclined surface, ${ }^{\circ}$

$\varepsilon$ clearness parameter (Perez model),

$\varepsilon\llcorner w$ long-wave emissivity,

$\theta$ angle of incidence of beam irradiance, ${ }^{\circ}$

$\theta_{z}$ zenith angle, ${ }^{\circ}$

$\rho$ solar reflectivity of the ground.

\section{REFERENCES}

Basińska, M., Ratajczak, K. and Tomczyk, J. (2018). Energy performance for residential building - comparison between theoretical method and real measurements. In: $10^{\text {th }}$ Conference on Interdisciplinary Problems in Environmental Protection and Engineering EKO-DOK 2018. [online], E3S Web of Conferences 44, pp. 1-8. Available at: https://www.e3sconferences.org/articles/e3sconf/abs/2018/19/contents/contents.html [Accessed 2 May 2019].

Cyrankowski, M., Wilkowski, J., Górski, J. and Chludzińska, D. (2014). The analysis of the energy demand for heating and cooling of the house built on the basis of the modernised Canadian wood-frame construction. Annals of Warsaw University of Life Sciences - SGGW, Forestry and Wood Technology, 88, pp. 42-45.

Firląg, S. and Piasecki, M. (2018). NZEB Renovation Definition in a Heating Dominated Climate: Case Study of Poland. Applied Scences, 8(9).

Frydrychowicz-Jastrzębska, G. and Bugała, A. (2015). Modeling the Distribution of Solar Radiation on a Two-Axis Tracking Plane for Photovoltaic Conversion. Energies, 8(2), pp. 1025-1041.

Grudzińska, M. (2016). Climatic Zones in Poland and the Demand for Heating in a Typical Residential Building. In: SBE16 Hamburg, Strategies, Stakeholders, Success factors. [online] ZEBAU - Centre for Energy, Construction, Architecture and the Environment $\mathrm{GmbH}$, pp. 228-237. Available at: https://publikationen.bibliothek.kit.edu/1000051699 [Accessed 2 May 2019]. 
Grudzińska, M. (2018). Validation of a dynamic simulation program according to EN ISO 15265. In: SOLINA 2018 - VII Conference SOLINA Sustainable Developmen: Architecture - Building Construction - Environmental Engineering and Protection Innovative Energy-Efficient Technologies - Utilization of Renewable Energy Sources. Available at: https://www.e3sconferences.org/articles/e3sconf/abs/2018/24/contents/contents.html [Accessed 2 May 2019].

Grudzińska, M. and Jakusik, E. (2015). The efficiency of a typical meteorological year and actual climatic data in the analysis of energy demand in buildings. Building Services Engineering Research and Technology, 36(6), pp. 658-669.

Grudzińska, M. and Jakusik, E. (2017). Energy performance of buildings in Poland on the basis of different climatic data. Indoor and Built Environment, 26(4), pp. 551566.

Hay, J.E. (1979). Calculation of monthly mean solar radiation for horizontal and inclined surfaces. Solar Energy, 23(4), pp. 301-307.

Jędrzejuk, H. and Dybiński, O. (2015). The influence of a heating system control program and thermal mass of external walls on the internal comfort in the Polish climate. Energy Procedia, 78, pp. 1087-1092.

Lis, P. (2018). Estimated potential for energy savings in heating residential buildings in Poland. In: SOLINA 2018 - VII Conference SOLINA Sustainable Developmen: Architecture - Building Construction - Environmental Engineering and Protection Innovative Energy-Efficient Technologies - Utilization of Renewable Energy Sources. Available at: https://www.e3sconferences.org/articles/e3sconf/abs/2018/24/contents/contents.html [Accessed 2 May 2019].

Mazurek, G. (2014). Estimation of Solar Irradiation on Inclined Surface Based on Web Databases. International Journal of Electronics and Telecommunications, 60(4), pp. 315-320.

Michalak, P. (2018). Calculation of the Global Solar Irradiance on Arbitrarily Oriented Tilted Surfaces According to the New PN-EN ISO 52010-1: 2017. District Heating, Heating, Ventilation [in Polish], 49(7), pp. 280-287.

MliR.gov.pl (2019). Typical Meteorological Years. The Ministry of Infrastructure and Development Official Website. [online] Available at: https://www.gov.pl/web/inwestycje-rozwoj/dane-do-obliczen-energetycznychbudynkow [Accessed 2 May 2019].

Muneer, T. and Satuja, G.S. (1989). Correlation between daily diffuse and global irradiation for the UK. Building Service Engineering, 6(3), pp. 103-108.

Nelken, K. and Zmudzka, E. (2016). TMY versus multi-year time series of meteorological conditions for the characterization of central Poland's suitability for photovoltaics. Meteorologische Zeitschrift, 26(1), pp. 21-31.

Panek, A. and Kwiatkowski, J. (2007). Method for calculating heating demand and energy requirements [in Polish]. Energia i Budynek, 7, pp. 9-13. Available at: http://www.buildup.eu/sites/default/files/content/A.D.Panek\%2CJ.Kwiatkowski.p df [Accessed 2 May 2019].

Perez, R., Ineichen, P., Seals, R., Michalsky, J. and Steward R. (1990). Modeling daylight availability and irradiance components from direct and global irradiance. Solar Energy, 44(5), pp. 271-289.

Polish Committee for Standardization, (2009). PN-EN ISO 13790:2009. Energy performance of buildings. Calculation of energy use for space heating and cooling. Warszawa.

Reindl, D.T., Beckman, W.A. and Duffie, J.A. (1990). Evaluation of Hourly Tilted Surface Radiation Models. Solar Energy, 45, pp. 9-17.

The Polish Committee for Standardization. (2017). PN-EN ISO 52010-1:2017. Energy performance of buildings - External climatic conditions - Part 1: Conversion of climatic data for energy calculations. Warszawa. 
Wierciński, Z. and Skotnicka-Siepsiak, A. (2012). Energy and exergy flow balances for traditional and passive detached houses. Technical Sciences, 15(1), pp. 15-33.

Włodarczyk, D. and Nowak H. (2009). Statistical analysis of solar radiation models onto inclined planes for climatic conditions of Lower Silesia in Poland. Archives of Civil and Mechanical Engineering, 9(2), pp. 127-144.

Wojdyga, K. (2008). An influence of weather conditions on heat demand in district heating systems. Energy and Buildings, 40(11), pp. 2009-2014.

\begin{abstract}
.
The paper presents calculations of global solar irradiance on inclined surfaces of any orientation in the hourly time step. For computational purposes there were used the data from typical meteorological years (TMY) available in a form of text files on the website of the Ministry of Infrastructure and Development. Hourly solar global horizontal irradiance from measurements from the file for Kraków was used as input for five anisotropic models (Hay, Muneer, Reindl, Perez and Perez according to the new PN-EN ISO 52010-1 standard). Direct normal and diffuse horizontal and then global irradiances were calculated. To illustrate the effects of using different models, for the exemplary residential building, monthly solar heat gains and heating demand was determined according to the monthly method of PN-EN ISO 13790. In comparison to the solar data from the TMY, an average decrease in the value of solar gains amounted $37 \%$, what resulted in an increase in the calculated heat demand of the building by $10 \%$. This is very important since this change takes place without any modernisation works.
\end{abstract}

Keywords: Diffuse irradiance, anisotropic model, sloped surface, typical meteorological year, EN-ISO 52010-1 